\title{
An open-label, one-year, noncomparative study to evaluate the safety and tolerability of intravitreal pegaptanib sodium in patients with diabetic macular edema
}

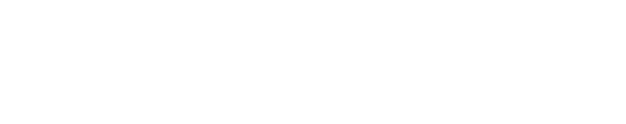

\author{
Sobha Sivaprasad' \\ Richard C Browning ${ }^{2}$ \\ Carla Starita ${ }^{2}$ \\ 'Consultant Ophthalmologist, King's \\ College Hospital, Denmark Hill, \\ London, ${ }^{2}$ Pfizer Ltd, Walton Oaks, \\ Dorking Road, Tadworth, Surrey, UK
}

Background: The purpose of this study was to evaluate the safety and tolerability of pegaptanib in patients with diabetic macular edema.

Methods: An open-label, multicenter, noncomparative, one-year study of approximately 500 patients was planned. Recruitment was terminated after enrollment of 46 patients. Enrolled patients were fully informed and reconsented; 12 patients elected to complete the study. Patients received intravitreal injections of pegaptanib $0.3 \mathrm{mg}$ once every 6 weeks or less frequently, as determined by the investigator. Clinical benefit was evaluated after the patient received two or more injections. Ocular and nonocular adverse events were closely monitored throughout the study.

Results: Compared with baseline, mean best-corrected visual acuity increased by week 6 . Ten patients reported ocular-related adverse events, none of which were severe, and eight patients reported nonocular adverse events, two of which were severe but unrelated to study treatment. Three serious adverse events, unrelated to study treatment, were reported.

Conclusion: In this limited set of patients with diabetic macular edema, pegaptanib appeared to be well tolerated with evidence of efficacy.

Keywords: pegaptanib, diabetic macular edema, safety, tolerability

\section{Introduction}

Diabetic macular edema (DME) is a complication of diabetic retinopathy occurring in patients with type 1 or type 2 diabetes. ${ }^{1-3}$ It is characterized by diffuse or cystic macular thickening with or without lipid exudation caused by breakdown of the inner and outer blood retinal barriers. If untreated, DME can lead to vision loss, and the condition is responsible for $4.8 \%$ of cases of blindness worldwide. ${ }^{4}$ Patient quality of life is affected at all stages of the disease, but may improve with treatment. ${ }^{1-3,5-7}$ As the incidence of diabetes increases worldwide ${ }^{8-10}$ so does the prevalence of DME. ${ }^{11,12}$ Approximately $10 \%$ of all adults with diabetes experience vision-threatening diabetic retinopathy, and half of these progress to developing DME. ${ }^{13}$ Until recently, the standard treatment for DME has been laser photocoagulation, with no approved therapeutic options available for those who fail to respond to laser therapy. Therefore, clinical research has been performed to identify safe and effective treatments that improve both visual function and quality of life for patients with DME.

In the past few years, several studies have demonstrated that treatment with vascular endothelial growth factor (VEGF) inhibitors can result in statistically
Correspondence: Sobha Sivaprasad

King's College Hospital, Denmark Hill, London, SE5 9RS, UK

Tel +4402032994548

Fax +4402032993738

Email senswathi@aol.com 
significant improvement of visual acuity in patients with DME. ${ }^{14-19}$ Pegaptanib sodium (Macugen ${ }^{\circledR}$; Pfizer Inc, New York, NY, USA) is an aptamer that binds with high specificity and affinity to $\mathrm{VEGF}_{165}$, a protein implicated in the pathogenesis of age-related macular degeneration ${ }^{20}$ and DME. ${ }^{21-23}$ Thus, pegaptanib acts as a VEGF antagonist and is currently approved for the treatment of age-related macular degeneration but not for DME. A Phase II/III trial demonstrated that compared with sham treatment, administration of intravitreal pegaptanib every 6 weeks for one year resulted in statistically significant improvement in visual acuity as measured by $\geq 10$-letter gains $(P=0.0047)$ and patient quality of life as measured by a greater than five-point difference in the National Eye Institute Visual Functioning Questionnaire 25. ${ }^{3}$

This Phase IIIb study was designed to extend and further evaluate the safety and tolerability of pegaptanib in patients with DME. However, soon after study initiation, the sponsor decided to withdraw the regulatory application for DME. Further recruitment of patients was immediately stopped. Patients already enrolled in the study were informed and given the opportunity to either withdraw or continue treatment until the end of the study upon providing written informed consent.

\section{Patients and methods}

\section{Patients}

This open-label, multicenter, noncomparative Phase IIIb trial (ClinicalTrials.gov identifier NCT01189461) was conducted in patients aged $\geq 18$ years with type 1 or type 2 diabetes and a documented clinical diagnosis of DME with proliferative or nonproliferative diabetic retinopathy and who, according to the investigator, could have benefited from anti-VEGF therapy. Over 500 patients were to be enrolled in the study. For enrollment, patients were required to have a bestcorrected visual acuity (BCVA) letter score between 78 and 24 inclusive (20/32 to 20/320 Snellen equivalents), intraocular pressure $\leq 21 \mathrm{mmHg}$, clear ocular media, and adequate pupillary dilatation. Furthermore, the treating investigator needed to certify that focal laser treatment could be deferred for $\geq 18$ weeks in the study eye. Key exclusion criteria were: prior scatter photocoagulation treatment within 4 months of study initiation or anticipated within the following 6 months; other reasons for macular edema, atrophy, scarring, or fibrosis involving the center of the macula; significant media opacities, including cataracts; any intraocular surgery within 4 months of study entry; previous vitrectomy; and previously documented glycated hemoglobin $>10 \%$ or recent evidence of uncontrolled diabetes. All patients provided written informed consent.

\section{Treatment}

Patients were administered intravitreal pegaptanib $0.3 \mathrm{mg}$ in the study eye under aseptic conditions by ophthalmologists experienced in the procedure. Patients were treated at baseline and at subsequent visits once every 6 weeks after BCVA evaluation, biomicroscopy, dilated fundus examinations in both eyes, and tonometry measurements. After the first two injections, additional injections could be administered less frequently than once every 6 weeks, as determined by the investigator. Clinical benefit was evaluated after two or more injections. Retreatment was left to the discretion of the investigator, and patients who demonstrated a clinical benefit could continue to receive intravitreal pegaptanib injections for up to 48 weeks.

\section{Endpoints}

The primary endpoint was the incidence of ocular and nonocular adverse events (AEs), defined as any untoward medical occurrence not necessarily having a causal relationship with the treatment. One secondary endpoint was the incidence of ocular and nonocular serious AEs, defined as any AE resulting in, but not limited to, death, is life-threatening, hospitalization, persistent disability, or congenital anomaly. All observed and reported AEs were recorded using Medical Dictionary for Regulatory Activities (MedDRA) version 15.0 throughout the study. Other secondary endpoints included the mean number of injections per patient and efficacy of treatment as evaluated by change in BCVA from baseline to end of treatment. BCVA was measured using retroilluminated modified Ferris-Bailey Early Treatment Diabetic Retinopathy Study charts starting at $4 \mathrm{~m}$. Complete ophthalmological examinations (including slit-lamp biomicroscopy, ophthalmoscopy, tonometry, BCVA measurements, and fundus examinations) were performed at screening, baseline, each treatment visit, and at follow-up. Applanation tonometry was performed for all patients at screening and to verify postinjection intraocular pressures $\geq 30 \mathrm{mmHg}$ lasting for $>30$ minutes post injection or for a reading of $\geq 30 \mathrm{mmHg}$ at any other time.

\section{Statistical analyses}

In total, 500 patients were to be enrolled based on a requirement of 459 patients, which would provide a $>99 \%$ chance of detecting at least one occurrence of any AE with a true 


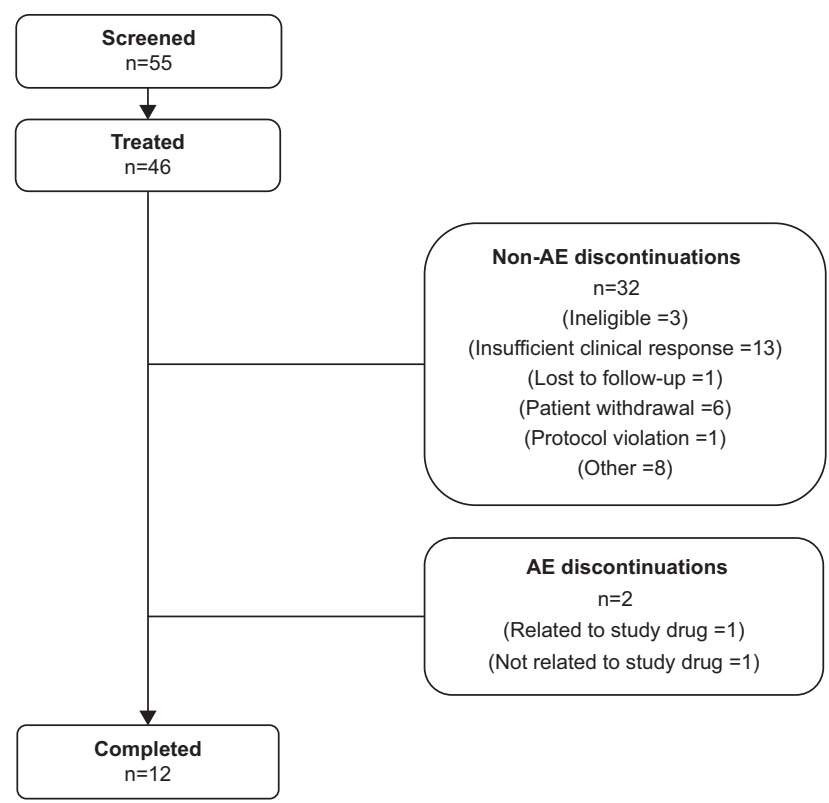

Figure I Patient disposition.

Abbreviation: $\mathrm{AE}$, adverse event.

underlying rate of one or more in 100. Descriptive statistics were used for reporting efficacy (BCVA scores and change from baseline in BCVA scores to each visit and end of study) and safety endpoints. Statistics are presented using observed data with no imputation for missing values.

Table I Baseline demographics of patients enrolled in the study

\begin{tabular}{|c|c|}
\hline Parameter & Patients $(n=46)$ \\
\hline Patients, n (\%) & $46(100.0)$ \\
\hline \multicolumn{2}{|l|}{ Sex, n (\%) } \\
\hline Male & $30(65.2)$ \\
\hline Female & $16(34.8)$ \\
\hline Mean (SD) age (years) & $65.0(10.6)$ \\
\hline \multicolumn{2}{|l|}{ Race, n (\%) } \\
\hline White & $42(9 \mid .3)$ \\
\hline Black & $\mathrm{I}(2.2)$ \\
\hline Asian & $2(4.3)$ \\
\hline Other & $\mathrm{I}(2.2)$ \\
\hline Median (range) duration since diagnosis & $2.4(0.0-14.7)$ \\
\hline \multicolumn{2}{|l|}{ of DME (years) } \\
\hline Mean (SD) baseline BCVA score (letters) & $58.9(16.5)$ \\
\hline Mean (SD) IOP (mmHg) & $15.9(2.6)$ \\
\hline \multicolumn{2}{|l|}{ Secondary diagnoses } \\
\hline Diabetes, n (\%) ${ }^{\mathrm{a}}$ & $\mathrm{I}(2.2)$ \\
\hline Mean duration since first diagnosis (years) & 22.3 \\
\hline Type I diabetes, n (\%) & $5(10.9)$ \\
\hline Mean duration since first diagnosis (years) & 23.0 \\
\hline Type 2 diabetes, $\mathrm{n}(\%)$ & $39(84.8)$ \\
\hline Mean duration since first diagnosis (years) & 14.9 \\
\hline Glaucoma, n (\%) & $\mathrm{I}(2.2)$ \\
\hline Mean duration since first diagnosis (years) & 11.3 \\
\hline
\end{tabular}

Note: ane patient was not classified.

Abbreviations: SD, standard deviation; DME, diabetic macular edema; BCVA best-corrected visual acuity; IOP, intraocular pressure.
Table 2 Drug treatments prior to start of study treatment in $\geq 25 \%$ of patients ${ }^{\mathrm{a}}$

WHO drug dictionary class (v02Q2)

Patients $(\mathrm{n}=\mathbf{4 6})$, n (\%)

Any prior drug treatment excluding diabetes

$42(91.3)$

and DME medications

Agents acting on the renin-angiotensin system 29 (63.0)

Serum lipid-reducing agents $22(47.8)$

Antithrombotic agents 18 (39.1)

Analgesics 14 (30.4)

Stomatological preparations ${ }^{\mathrm{b}} \quad$ I4 (30.4)

Drugs for acid-related disorders 12 (26.1)

Notes: ${ }^{2}$ Excluding treatments given for diabetes or DME. ${ }^{b} A l l$ acetylsalicylic acid use (14 patients) has been reported in this table as a stomatological preparation.

Abbreviations: WHO, World Health Organization; DME, diabetic macular edema.

\section{Results}

\section{Patient disposition}

Fifty-five patients were screened prior to termination of recruitment. Of these, 46 patients were enrolled and 12 completed the study (Figure 1). The baseline characteristics of the 46 patients enrolled prior to termination of enrollment are given in Table 1. When enrollment was stopped, patients already entered into the study were informed and given the option of withdrawing or continuing in the study.

Of the 46 patients enrolled, 42 (91.3\%) had received prior drug treatment for conditions other than diabetes or DME (Table 2) and an equal number were receiving concomitant treatments for conditions other than diabetes or DME during the study (Table 3). The median duration of study treatment for the 46 patients was 13.6 weeks.

Table 3 Concomitant drug treatments in $\geq 25 \%$ of total patients $^{\mathrm{a}}$

\begin{tabular}{ll}
\hline WHO drug dictionary class (v02Q2) & $\begin{array}{l}\text { Patients (n=46), } \\
\mathbf{n}(\%)\end{array}$ \\
\hline $\begin{array}{l}\text { Any concomitant drug treatment excluding } \\
\text { diabetes and DME medications }\end{array}$ & $42(91.3)$ \\
Agents acting on the renin-angiotensin system & $30(65.2)$ \\
Ocular medications & $24(52.2)$ \\
Serum lipid-reducing agents & $23(50.0)$ \\
Antibacterials for systemic use & $21(45.7)$ \\
Antithrombotic agents & $19(41.3)$ \\
Analgesics & $15(32.6)$ \\
Stomatological preparations ${ }^{\mathrm{b}}$ & $16(34.8)$ \\
Ophthalmological and otological preparations & $13(28.3)$ \\
Drugs for acid-related disorders & $13(28.3)$
\end{tabular}

Notes: aExcluding treatments given for diabetes or DME. 'D $\mathrm{O}$ the 16 patients who are reported as receiving concomitant stomatological preparations, 15 patients received acetylsalicyclic acid (all acetylsalicylic acid use has been reported in this table as stomatological) and one patient received benzydamine hydrochloride.

Abbreviations: WHO, World Health Organization; DME, diabetic macular edema. 
Table 4 Mean \pm SD BCVA scores by study visit

\begin{tabular}{lll}
\hline Study visit & $\begin{array}{l}\text { Patients }(\mathbf{n}=\mathbf{4 6}), \\
\mathbf{n}(\%)\end{array}$ & $\begin{array}{l}\text { Mean } \pm \text { SD } \\
\text { BCVA score }\end{array}$ \\
\hline Baseline & $42(91.3)$ & $58.9 \pm 16.5$ \\
Week 6 & $36(78.3)$ & $63.1 \pm 14.1$ \\
Week I2 & $34(73.9)$ & $63.4 \pm 13.2$ \\
Week 18 & $32(69.6)$ & $60.6 \pm 16.5$ \\
Week 24 & $22(47.8)$ & $65.6 \pm 12.7$ \\
Week 30 & $20(43.5)$ & $65.1 \pm 10.7$ \\
Week 36 & $12(26.1)$ & $62.3 \pm 11.7$ \\
Week 40 & II (23.9) & $66.6 \pm 10.8$ \\
Week 48 & $14(30.4)$ & $65.0 \pm 12.2$ \\
Week 54 & $5(10.9)$ & $68.6 \pm 11.8$ \\
$>$ Week 54 & I (2.2) & 78.0 \\
Final visit & $42(91.3)$ & $63.4 \pm 13.1$ \\
\hline
\end{tabular}

Abbreviations: SD, standard deviation; BCVA, best-corrected visual acuity.

\section{Efficacy and safety}

Compared with baseline, mean BCVA increased noticeably by week 6 and remained steady, with further small increases thereafter (Table 4). Owing to withdrawals, the results at later visits are based on a small number of patients. Overall, the mean total number of injections in all patients was 3.2, with a median of 3.0 and a range of 1.0-6.0. The mean interval between injections was 7.7 weeks, with a median of 6.5 weeks.

The individual data for the 12 patients who completed the study are given in Table 5. The BCVA change between baseline and the follow-up visit was $\geq 10$ letters in four of 12 patients, and $>5$ letters in seven of 12 patients.

Sixteen $(34.8 \%)$ of the 46 patients enrolled in the study reported AEs, of which four (8.7\%) reported treatmentrelated AEs (Table 6). Seventeen ocular-related AEs (none severe) were reported by ten $(21.7 \%)$ patients. Nineteen nonocular, all-causality AEs (two severe but not related to treatment) were reported by eight $(17.4 \%)$ patients (Table 7). One moderate hypersensitivity skin reaction was observed, but was reported to be unrelated to study treatment. Three patients had serious AEs (cerebrovascular accident, myocardial infarction, and lung malignancy) that were reported as unrelated to study treatment by the investigator.

\section{Discussion}

Several clinical and preclinical studies have demonstrated the role of VEGF in the pathogenesis of DME, and ranibizumab is currently the only anti-VEGF agent approved in the European Union for the treatment of visual impairment due to DME. ${ }^{3,19,24-28}$

Two clinical studies were performed to study the efficacy and safety of pegaptanib in patients with DME. ${ }^{19,24}$ The primary objective of the study reported here was to further assess the safety and tolerability of pegaptanib in patients with documented DME which, in the opinion of the treating physician, would benefit from anti-VEGF therapy. As such, neither assessment of central macular thickness nor specific standardized retreatment criteria were included in the study design so as to better reflect real-world clinical practice. However, recruitment for this study was stopped following the sponsor's decision to withdraw the marketing application for this indication. Thus, the primary limitation of this study is the very small number of patients enrolled (46 of the planned 500). The study is further limited by only 12 patients deciding to complete the study after being informed of the sponsor's decision. Therefore, the sample size for this study was too small for any statistical analyses of the data. Consequently, the data reported here must be interpreted with great caution. Nevertheless, the results of this study are consistent

Table 5 Relevant data for individual patients completing study

\begin{tabular}{|c|c|c|c|c|c|c|c|c|c|c|}
\hline \multirow[t]{2}{*}{ Patient } & \multirow[t]{2}{*}{ Age } & \multicolumn{2}{|c|}{ Duration (years) } & \multirow{2}{*}{$\begin{array}{l}\text { Type of } \\
\text { diabetes }\end{array}$} & \multirow{2}{*}{$\begin{array}{l}\text { Receiving } \\
\text { statins? }\end{array}$} & \multicolumn{2}{|c|}{ Laser treatment in study eye } & \multicolumn{2}{|c|}{ VA in study eye } & \multirow[t]{2}{*}{ IVT } \\
\hline & & DME & Diabetes & & & Past history & During study & Baseline & Follow-up & \\
\hline I & 57 & 0.5 & 15.4 & 2 & No & No & No & 28 & 62 & 4 \\
\hline 2 & 43 & 0 & 22.3 & NC & No & Yes & No & 73 & 85 & 3 \\
\hline 3 & 61 & 5.0 & 5.0 & 2 & Yes & Yes & No & 47 & 68 & 3 \\
\hline 4 & 64 & 0.9 & 2.2 & 2 & No & Yes & No & 43 & 41 & 2 \\
\hline 5 & 52 & 1.3 & 16.8 & 2 & No & Yes & No & 59 & 56 & 3 \\
\hline 6 & 57 & 2.2 & 28.4 & 2 & Yes & Yes & Yes & 62 & 76 & 5 \\
\hline 7 & 81 & 0.2 & 22.1 & 2 & No & No & No & 75 & 82 & 3 \\
\hline 8 & 68 & 0.1 & 13.4 & 2 & Yes & No & No & 70 & 78 & 4 \\
\hline 9 & 77 & 0.7 & 14.1 & 2 & Yes & Yes & No & 72 & 78 & 4 \\
\hline 10 & 62 & 10.4 & 26.3 & I & No & Yes & No & 52 & 53 & 3 \\
\hline 11 & 66 & 3.6 & 23.0 & 2 & No & Yes & No & 69 & 69 & 5 \\
\hline 12 & 64 & 2.0 & 23.0 & 2 & No & Yes & No & 71 & 65 & 6 \\
\hline
\end{tabular}

Abbreviations: DME, diabetic macular edema; VA, visual acuity; IVT, intravitreal treatment; NC, not classified. 
Table 6 Summary of treatment-emergent AEs

\begin{tabular}{|c|c|c|}
\hline Parameter & $\begin{array}{l}\text { All causality, } \\
\text { n (\%) }\end{array}$ & $\begin{array}{l}\text { Treatment-related, } \\
\text { n (\%) }\end{array}$ \\
\hline AEs (n) & 37 & 5 \\
\hline Patients with AEs & $16(34.8)$ & $4(8.7)$ \\
\hline Patients with SAEs & $3(6.5)$ & 0 \\
\hline Patients with severe AEs & $2(4.3)$ & 0 \\
\hline Patients discontinued owing to AEs & $2(4.3)$ & $\mathrm{I}(2.2)$ \\
\hline Patients with dose reduced or temporary discontinuation owing to AEs & $\mathrm{I}(2.2)$ & $\mathrm{I}(2.2)$ \\
\hline
\end{tabular}

Abbreviations: $A E$, adverse event; $S A E$, serious adverse event.

with those reported for another small study of 20 patients in whom pegaptanib was demonstrated to be efficacious and safe over a 12 -month period. ${ }^{29}$

Treatment-related AEs were mild or moderate in severity in 46 patients receiving at least one dose of pegaptanib.
There were no severe drug-related AEs observed or deaths reported, suggesting that pegaptanib was well tolerated in this cohort of patients with DME. These data are consistent with those reported for the Phase II/III trials comparing intravitreal pegaptanib injections with sham treatment. . $19,24,25^{2}$

Table 7 All-causality and treatment-related incidence and severity of treatment-emergent ocular AEs

\begin{tabular}{|c|c|c|c|}
\hline \multirow[t]{2}{*}{ MedDRA preferred term } & \multicolumn{3}{|c|}{ All causality (treatment-related), $n$} \\
\hline & Mild & Moderate & Severe \\
\hline Ocular AEs & $13(2)$ & $4(2)$ & 0 \\
\hline Macular edema & $2(0)^{\mathrm{a}}$ & I (0) & 0 \\
\hline Visual acuity reduced & $\mathrm{I}(0)$ & $I(0)$ & 0 \\
\hline Vitreous floaters & $I(I)$ & 0 & 0 \\
\hline Cataract & $I(1)$ & 0 & 0 \\
\hline IOP increased & 0 & $I(I)$ & 0 \\
\hline Uveitis & 0 & $I(1)$ & 0 \\
\hline Conjunctival hemorrhage & $\mathrm{I}(0)$ & 0 & 0 \\
\hline Conjunctival hyperemia & $I(0)$ & 0 & 0 \\
\hline Conjunctivitis & $I(0)$ & 0 & 0 \\
\hline Eye discharge & I (0) & 0 & 0 \\
\hline Eye pain & $I(0)$ & 0 & 0 \\
\hline Eye pruritus & $I(0)$ & 0 & 0 \\
\hline Eyelid ptosis & $I(0)$ & 0 & 0 \\
\hline Maculopathy & $\mathrm{I}(0)^{\mathrm{a}}$ & 0 & 0 \\
\hline Nonocular AEs & $I I(I)$ & $6(0)$ & $2(0)$ \\
\hline Wheezing & $\mathrm{I}(\mathrm{I})^{\mathrm{a}}$ & 0 & 0 \\
\hline Anemia & $\mathrm{I}(0)^{\mathrm{a}}$ & 0 & 0 \\
\hline Gastric polyps & $\mathrm{I}(0)^{\mathrm{a}}$ & 0 & 0 \\
\hline Gastrointestinal hypermotility & $\mathrm{I}(0)^{\mathrm{a}}$ & 0 & 0 \\
\hline Hiatus hernia & $\mathrm{I}(0)^{\mathrm{a}}$ & 0 & 0 \\
\hline Upper respiratory tract infection & $\mathrm{I}(0)^{\mathrm{a}}$ & 0 & 0 \\
\hline Carcinoembryonic antigen increased & $\mathrm{I}(0)^{\mathrm{a}}$ & 0 & 0 \\
\hline Lung neoplasm malignant & $\mathrm{I}(0)^{\mathrm{a}}$ & 0 & 0 \\
\hline Headache & $\mathrm{I}(0)^{\mathrm{a}}$ & 0 & 0 \\
\hline Renal colic & $\mathrm{I}(0)^{\mathrm{a}}$ & 0 & 0 \\
\hline Hypertension & $\mathrm{I}(0)$ & 0 & 0 \\
\hline Biopsy vocal cord & 0 & $I(0)$ & 0 \\
\hline Anxiety & 0 & $I(0)$ & 0 \\
\hline Cough & 0 & $I(0)$ & 0 \\
\hline Asthenia & 0 & $I(0)$ & 0 \\
\hline Gastroenteritis & 0 & $I(0)$ & 0 \\
\hline Diarrhea & 0 & $I(0)$ & 0 \\
\hline Cerebrovascular accident & 0 & 0 & $I(0)$ \\
\hline Myocardial infarction & 0 & 0 & $I(0)$ \\
\hline
\end{tabular}

Note: aNot likely to be drug related.

Abbreviations: AE, adverse event; MedDRA, Medical Dictionary for Regulatory Activities; IOP, intraocular pressure. 
Evidence of a modest initial clinical benefit, measured as improvement in BCVA, was observed in the patients by week 6 . Although data are limited, this benefit appears to be sustained throughout the study; of the 12 patients completing the study, about $30 \%$ gained $>10$ letters of BCVA, while approximately $60 \%$ gained $>5$ letters of BCVA. These data appear to be consistent with those reported in the Phase II/III trials. ${ }^{3,19,24}$ However, the number of patients in this study is too small to derive any definitive conclusions. The magnitude and duration of the benefit suggested in this study for patients with DME will need to be confirmed in a larger study powered to address these questions.

\section{Acknowledgments}

Statistical evaluation of the data and support was provided by Rachel Moate, formerly of Quanticate Ltd, Hertfordshire, UK. We are very grateful to all of the patients and investigators and the study team who were involved in the study and provided data for analysis.

\section{Author contributions}

SS recruited patients for the study, and participated in interpretation of the analysis and data, development of the manuscript, and final approval of the manuscript. RCB was involved in the design of the study, monitoring of safety, analysis and interpretation of the data, development of the manuscript, and final approval of the manuscript. CS was involved in the design of the study, analysis and interpretation of the data, development of the manuscript, and final approval of the manuscript.

\section{Disclosure}

SS has received research grants from and has attended advisory board meetings for Novartis, Allergan, and Bayer. RCB and CS are employees of Pfizer Ltd, which funded the study. Editorial support for writing and styling the paper for journal submission was provided by Mukund Nori of Engage Scientific Solutions and was funded by Pfizer Inc, New York, NY, USA.

\section{References}

1. Davidov E, Breitscheidel L, Clouth J, Reips M, Happich M. Diabetic retinopathy and health-related quality of life. Graefes Arch Clin Exp Ophthalmol. 2009;247(2):267-272.

2. Hariprasad SM, Mieler WF, Grassi M, Green JL, Jager RD, Miller L. Vision-related quality of life in patients with diabetic macular oedema. Br J Ophthalmol. 2008;92(1):89-92.

3. Loftus JV, Sultan MB, Pleil AM. Changes in vision- and health-related quality of life in patients with diabetic macular edema treated with pegaptanib sodium or sham. Invest Ophthalmol Vis Sci. 2011;52(10): $7498-7505$
4. Resnikoff S, Pascolini D, Etya'ale D, et al. Global data on visual impairment in the year 2002. Bull World Health Organ. 2004;82(11): 844-851.

5. Scanlon PH, Martin ML, Bailey C, Johnson E, Hykin P, Keightley S. Reported symptoms and quality-of-life impacts in patients having laser treatment for sight-threatening diabetic retinopathy. Diabet Med. 2006;23(1):60-66.

6. Sharma S, Oliver-Fernandez A, Liu W, Buchholz P, Walt J. The impact of diabetic retinopathy on health-related quality of life. Curr Opin Ophthalmol. 2005;16(3):155-159.

7. Tranos PG, Topouzis F, Stangos NT, et al. Effect of laser photocoagulation treatment for diabetic macular oedema on patient's vision-related quality of life. Curr Eye Res. 2004;29(1):41-49.

8. International Diabetes Federation. IDF Diabetes Atlas. 5th ed. 2011. Available from: http://www.idf.org/diabetesatlas. Accessed September 4, 2012.

9. Farag YMK, Gaballa MR. Diabesity: an overview of a rising epidemic. Nephrol Dial Transplant. 2011;26(1):28-35.

10. Kolb H, Mandrup-Poulsen T. The global diabetes epidemic as a consequence of lifestyle-induced low-grade inflammation. Diabetologia. 2010;53(1):10-20.

11. Klein R, Knudtson MD, Lee KE, Gangnon R, Klein BE. The Wisconsin Epidemiologic Study of Diabetic Retinopathy XXII. The twentyfive-year progression of retinopathy in persons with type 1 diabetes. Ophthalmology. 2008;115(11):1859-1868.

12. Rubino A, Rousculp MD, Davis K, Wang J, Girach A. Diagnosed diabetic retinopathy in France, Italy, Spain, and the United Kingdom. Prim Care Diabetes. 2007;1(2):75-80.

13. Wong TY, Cheung N, Tay WT, et al. Prevalence and risk factors for diabetic retinopathy: the Singapore Malay Eye Study. Ophthalmology. 2008;115(11):1869-1875.

14. Elman MJ, Aiello LP, Beck RW, et al. Randomized trial evaluating ranibizumab plus prompt or deferred laser or triamcinolone plus prompt laser for diabetic macular edema. Ophthalmology. 2010;117(6): 1064-1077.e35.

15. Massin P, Bandello F, Garweg JG, et al. Safety and efficacy of ranibizumab in diabetic macular edema (RESOLVE study): a 12-month, randomized, controlled, double-masked, multicenter phase II study. Diabetes Care. 2010;33(11):2399-2405.

16. Michaelides M, Kaines A, Hamilton RD, et al. A prospective randomized trial of intravitreal bevacizumab or laser therapy in the management of diabetic macular edema (BOLT study) 12-month data: report 2. Ophthalmology. 2010;117(6):1078-1086.e2.

17. Mitchell P, Bandello F, Schmidt-Erfurth U, et al. The RESTORE study: ranibizumab monotherapy or combined with laser versus laser monotherapy for diabetic macular edema. Ophthalmology. 2011;118(4): 615-625.

18. Nguyen QD, Shah SM, Heier JS, et al. Primary end point (six months) results of the Ranibizumab for Edema of the mAcula in diabetes (READ-2) study. Ophthalmology. 2009;116(11):2175-2181.e1.

19. Sultan MB, Zhou D, Loftus J, Dombi T, Ice KS. A phase $2 / 3$, multicenter, randomized, double-masked, 2-year trial of pegaptanib sodium for the treatment of diabetic macular edema. Ophthalmology. 2011; 118(6):1107-1118.

20. Kliffen M, Sharma HS, Mooy CM, Kerkvliet S, de Jong PT. Increased expression of angiogenic growth factors in age-related maculopathy. Br J Ophthalmol. 1997;81(2):154-162.

21. Adamis AP, Miller JW, Bernal MT, et al. Increased vascular endothelial growth factor levels in the vitreous of eyes with proliferative diabetic retinopathy. Am J Ophthalmol. 1994;118(4):445-450.

22. Aiello LP, Avery RL, Arrigg PG, et al. Vascular endothelial growth factor in ocular fluid of patients with diabetic retinopathy and other retinal disorders. N Engl J Med. 1994;331(22):1480-1487.

23. Funatsu H, Yamashita H, Noma H, Mimura T, Yamashita T, Hori S. Increased levels of vascular endothelial growth factor and interleukin-6 in the aqueous humor of diabetics with macular edema. Am J Ophthalmol. 2002;133(1):70-77. 
24. Cunningham ET Jr, Adamis AP, Altaweel M, et al. A phase II randomized double-masked trial of pegaptanib, an anti-vascular endothelial growth factor aptamer, for diabetic macular edema. Ophthalmology. 2005;112(10):1747-1757.

25. Nicholson BP, Schachat AP. A review of clinical trials of anti-VEGF agents for diabetic retinopathy. Graefes Arch Clin Exp Ophthalmol. 2010;248(7):915-930.

26. Querques G, Bux AV, Fusco AR, Iaculli C, Delle Noci N. Pegaptanib sodium versus pegaptanib sodium combined with macular laser photocoagulation or laser alone for diabetic macular edema. J Ophthalmol. 2009;2009:672178.
27. Querques G, Bux AV, Martinelli D, Iaculli C, Noci ND. Intravitreal pegaptanib sodium (Macugen) for diabetic macular oedema. Acto Ophthalmol. 2009;87(6):623-630.

28. Adamis AP, Altaweel M, Bressler NM, et al. Changes in retinal neovascularization after pegaptanib (Macugen) therapy in diabetic individuals. Ophthalmology. 2006;113(1):23-28.

29. Pacella E, La Torre G, Impallara D, et al. Efficacy and safety of the intravitreal treatment of diabetic macular edema with pegaptanib: a 12-month follow-up. Clin Ter. 2013;164(2):e121-e126.
Clinical Ophthalmology

\section{Publish your work in this journal}

Clinical Ophthalmology is an international, peer-reviewed journal covering all subspecialties within ophthalmology. Key topics include: Optometry; Visual science; Pharmacology and drug therapy in eye diseases; Basic Sciences; Primary and Secondary eye care; Patien Safety and Quality of Care Improvements. This journal is indexed on

Submit your manuscript here: http://www.dovepress.com/clinical-ophthalmology-journal

\section{Dovepress}

PubMed Central and CAS, and is the official journal of The Society of Clinical Ophthalmology (SCO). The manuscript management system is completely online and includes a very quick and fair peer-review system, which is all easy to use. Visit http://www.dovepress.com/ testimonials.php to read real quotes from published authors. 